\title{
Challenging Aspects in Evaluating the Potential Danger of Space Objects Breakups and Collisions for Space Flights
}

\author{
Vitaly Adushkin ${ }^{\mathrm{a}}$, Oleg Aksenov ${ }^{\mathrm{b}}$, Stanislav Veniaminov ${ }^{\mathrm{b} *}$, Stanislav Kozlov ${ }^{\mathrm{a}}$ \\ anstitute of Geosphere Dynamics, RAS, Moscow, Russia

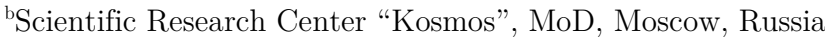 \\ *Email: sveniami@gmail.com
}

\begin{abstract}
The increasing near-Earth space (NES) exploration with its technogeneous contamination, and the resulting growth of space objects breakups risk for space flights makes more urgent the problem of estimating this danger, an adequate and accurate estimate being very important. In practice, given the complexity of obtaining the accurate estimates of this characteristic because of the large uncertainty in the initial data, it is a common practice simplifying the calculations, neglecting a set of factors, included some essential ones. In this work, some challenging aspects in evaluating and using the estimates of potential danger of space objects breakups and possible ways of improving these estimates are discussed.
\end{abstract}

Keywords: Space flight, orbital debris, manmade contamination, near-Earth space, breakup, collision, fragmentation

\section{Introduction}

As the technogenic contamination of NES increases, the same happens with the danger of space objects (SOs) breakups due to explosions and collisions of active spacecraft with orbital debris (OD) and OD with OD. This makes the problem of obtaining the estimates of the danger, as well as their adequacy mostly urgent [1]. More specifically, from the point of view of the space activities safety, objectively dangerous is both the breakups themselves and very simplified approaches to their assessment.

\section{The Danger of SOs Collisions}

Almost universally accepted is the recognition of the threat of collision of International Space Station (ISS) with OD larger than $1 \mathrm{~cm}[2,3]$. In particular, this danger does not strongly depend on the size of the hitting particle, but on its mass $m$ and much more on the relative speed $v_{r e l}$ with respect to the ISS. In fact, these two factors only partially characterize the energy released after collision which can potentially destroy, or damage, the spacecraft, or some of its subsystems:

$$
E_{\text {destr }}=k m v^{2}{ }_{r e l}
$$

where $k$ is a coefficient of proportionality depending on a number of circumstances of the collision event. For example these are the angle of the velocity vector of the hitting particle relative to the surface of the spacecraft, the susceptibility to impacts of the hit point of the spacecraft, the frailness and the melting point of the particle material.

The danger of small OD (for space activities) is often undervalued. A striking example of a great danger of collision with a very small OD is the Russian metrological satellite "Blitz" collided with a microparticle with mass $\sim 0.035 \mathrm{~g}$, size of $\sim 3 \mathrm{~mm}$, and relative velocity about $12.3 \mathrm{~km} / \mathrm{s}$. The satellite was destroyed and two fragments were cataloged and have been tracked. Moreover, the density of small OD fluxes at the height of the accident is $4-5$ orders of magnitude larger than the one of the cataloged SOs $[2,9]$.

Small OD (in the first place in Low Earth Orbits (LEO)) is burnt down in the atmosphere relatively rapidly (because of an area-to-mass $(\mathrm{A} / \mathrm{M})$ ratio greater than for large $\mathrm{OD}$ ). At the same time, a great amount of small OD is being constantly observed. Therefore, really small OD are produced more intensively than what it is estimated by suitable observations. In other words, we succeed to observe 
only a slight part of OD (because of insufficient and inadequate facilities capable of observing small OD, especially on higher than LEO orbits). This inference is confirmed also by our studies, presenting the lifetime of small OD of different sizes, taking into account only the atmosphere drag during the periods of maximum and minimum of solar activity (SA) levels (Figs 1. 2) and data by NASA (Table 1).

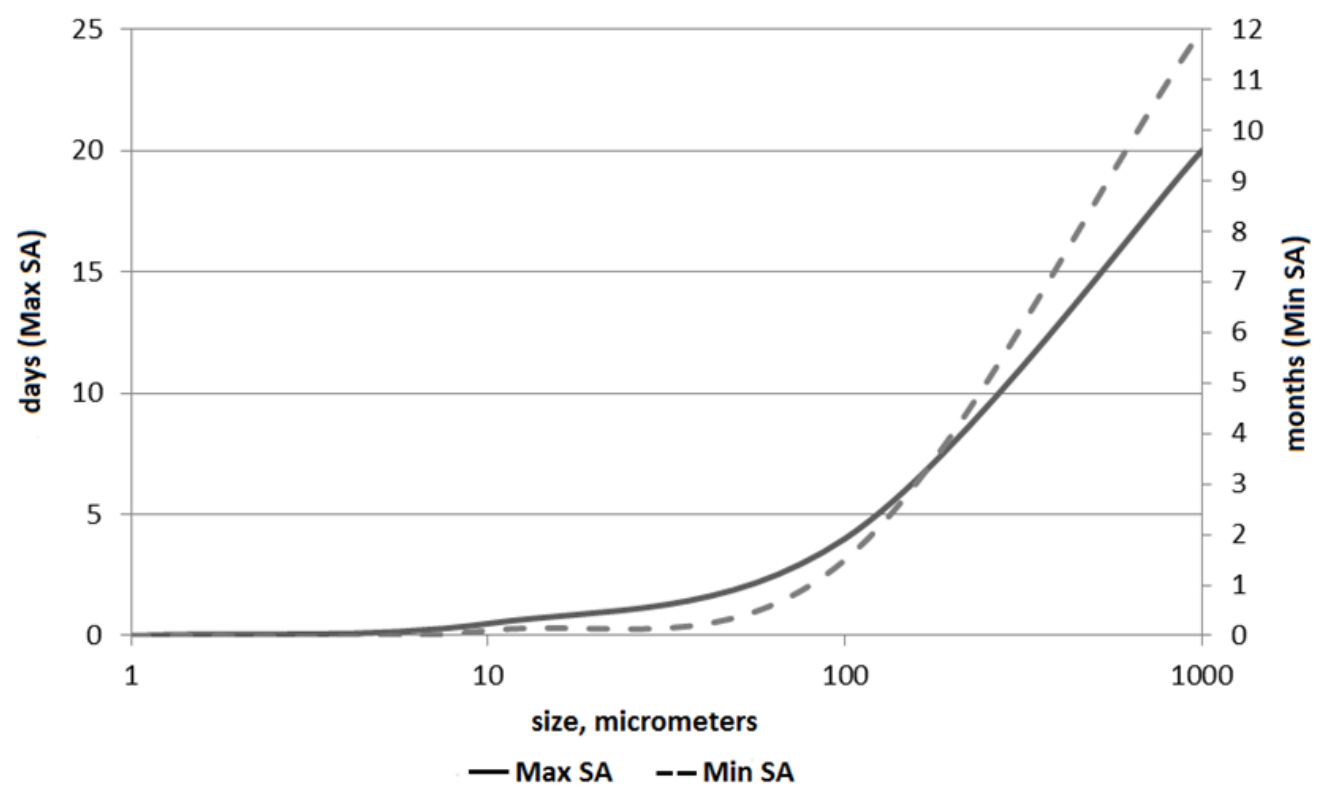

Figure 1. Lifetime of small OD at the height $600 \mathrm{~km}$ during the periods of maximum and minimum of solar activity levels

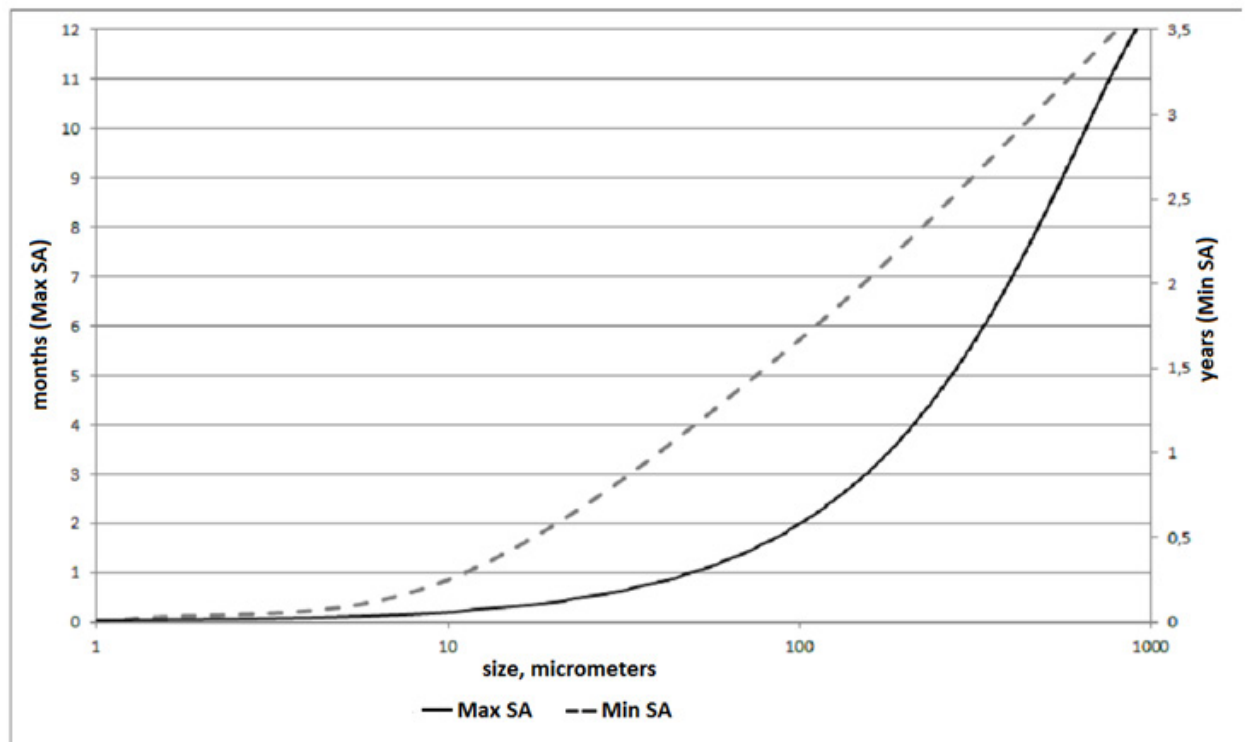

Figure 2. Lifetime of small OD in the orbit $600 \mathrm{~km} \times 1400 \mathrm{~km}$ during the periods of maximum and minimum of solar activity levels 
Table 1. Orbital lifetimes for OD of different sizes in various orbits considering only atmospheric drag. The terms in parentheses denote the lifetime for solar maximum and the bracketed value is for solar minimum [11].

\begin{tabular}{ccccc}
\hline 1 & 2 & 3 & 4 & 5 \\
\hline orbit, $\mathrm{km}$ & 1 micron & 10 micron & 100 micron & $1 \mathrm{~mm}$ \\
$200 / 200$ & $<1$ day & $<1$ day & $<1$ day & $<1$ day \\
$200 / 1000$ & $<1$ day & $<1$ day & $<1$ day & $(<1$ day $)$ \\
& & $(<$ days $]$ \\
$600 / 600$ & $<1$ day & {$[4$ days $]$} & $(3$ days $)$ & $(20$ days $)$ \\
& $(<1$ day $)$ & $(5$ days $)$ & $(2 \mathrm{mths}]$ & {$[1 \mathrm{yr}]$} \\
$600 / 1400$ & {$[9$ days $]$} & {$[3$ mths $]$} & {$[2 \mathrm{yrs}]$} & {$[3.5 \mathrm{yrs}]$} \\
\hline
\end{tabular}

At the same time, these graphs visually show how dramatically much the lifetime of small OD is affected by its size, its orbit height, and the solar activity level.

Many results of modeling show [9] that collisions of OD every year give birth to about 30000000 small fragments, with size 1-2.5 mm, $10 \%$ of them incinerating in the Earth's atmosphere. The main source of generation of small fragments is the mutual collision of non-cataloged SOs. As a result, at a height of $850 \mathrm{~km}$ the number of particles less than $2.5 \mathrm{~mm}$ exceeds by $4-5$ orders of magnitude the one of the cataloged SOs.

Table 2. The number of impacts of particles with size of the order of 100 micron on running spacecraft during the flight in the $50 \mathrm{~km}$ zone of the indicated average altitude [11].

\begin{tabular}{cccccc}
\hline 1 & 2 & 3 & 4 & 5 & 6 \\
\hline program & $\begin{array}{c}\text { average } \\
\text { altitude } \\
(\mathrm{km})\end{array}$ & $\begin{array}{c}\text { number of } \\
\text { impacts }\end{array}$ & $\begin{array}{c}\text { duration of } \\
\text { expos. } \\
\text { (years) }\end{array}$ & $\begin{array}{c}\text { surface exposed } \\
\left(\mathrm{m}^{2}\right)\end{array}$ & $\begin{array}{c}\text { flux (impacts } / \mathrm{m}^{2} \text { per } \\
\text { year) }\end{array}$ \\
LDEF & $350-500$ & 855 & 5.7 & 150 & 1 \\
Solarmax & 575 & 20 & 4 & 204 & 2 \\
Mir & 375 & 5 & 1.6 & 0.2 & 0.9 \\
EuReCa & 502 & 1080 & 0.9 & 21 & 30 \\
Hubble(solar & 614 & 750 & 3.6 & 210 \\
panels) & & & & 20 & 10 \\
\hline
\end{tabular}

Finally, the post-mission laboratory analysis of SOs many years exposed in space, then retrieved to the Earth, provides the next persuasive data on the flux density of small OD (see Table 2).

Unfortunately, these very important (to compose the notion of small OD flows) experiments have been carried out only at heights of up to $600 \mathrm{~km}$. At higher altitudes, the large deficit of highly demanded measurements of small debris, does not allow performing similar reports for such heights. These data refers to the period 1980 - 1993. If these experiments were conducted in the last few years, the results would have been more impressive, because the on-board detectors of OD impacts would have indicated a significant increase in its number in all orbital regions.

So, the aforementioned conventional approach for the evaluation of danger of breakups and collisions for space activities results to be harsh, if not incorrect, and it needs to be corrected.

\section{The Danger of SOs Breakups}

One more aspect of the problem concerns not only collisions of SOs but also breakups or fragmentation in general (in view of different causes) [4]. It is an assessment of danger of SOs breakups to space activities. At first glance, breakups producing the largest number of fragments are the most dangerous for active spacecraft. And this is more or less true in the period of time closest to the time of the breakup. However, in the longer term, the list of the most potentially hazardous breakups will change. It 
depends on the height and eccentricity of the parent SO and its fragments orbits, their sizes, the ratio of their surface area to mass, the character of spray of fragments and some other factors. The fragments of breakup may quickly burn up in the atmosphere or long stay in orbit. So, as rightly noted by Ph. AnzMeador [5], a more correct criterion of the danger of the "past" breakup in orbit at the current time would be the amount of debris remaining in orbit up to the current time.

Table 3. Ranging of the breakup relative danger

\begin{tabular}{|c|c|c|c|c|c|c|c|c|}
\hline 1 & 2 & 3 & 4 & 5 & 6 & 7 & 8 & 9 \\
\hline name & $\begin{array}{l}\text { year of } \\
\text { launch }\end{array}$ & $\begin{array}{c}\text { year of } \\
\text { breakup }\end{array}$ & $\begin{array}{l}\text { altitude of } \\
\text { breakup, } \\
\text { km }\end{array}$ & $\begin{array}{l}\text { cataloged } \\
\text { debris } \boldsymbol{N}_{1}^{i}\end{array}$ & $\begin{array}{c}\text { debris } \\
\text { remaining in } \\
\text { orbit } \boldsymbol{N}_{t}^{i}\end{array}$ & $\begin{array}{l}\text { cause of } \\
\text { breakup }\end{array}$ & $\mathrm{R}_{1}$ & $\mathbf{R}_{\mathrm{t}}$ \\
\hline Fengyun-1C & 1999 & 2007 & 850 & 3428 & 2880 & $\begin{array}{l}\text { intentional } \\
\text { collision }\end{array}$ & 1 & 1 \\
\hline Cosmos 2251 & 1993 & 2009 & 790 & 1668 & 1141 & $\begin{array}{c}\text { accidental } \\
\text { collision }\end{array}$ & 2 & 2 \\
\hline RB Step-2 & 1994 & 1996 & 625 & 754 & 84 & $\begin{array}{l}\text { accidental } \\
\text { explosion }\end{array}$ & 3 & 11 \\
\hline Iridium 33 & 1997 & 2009 & 790 & 628 & 364 & $\begin{array}{l}\text { accidental } \\
\text { collision }\end{array}$ & 4 & 3 \\
\hline Cosmos 2421 & 2006 & 2008 & 419 & 509 & 0 & unknown & 5 & 16 \\
\hline RB SPOT-1 & 1986 & 1986 & 805 & 498 & 32 & $\begin{array}{l}\text { accidental } \\
\text { explosion }\end{array}$ & 6 & 14 \\
\hline RB OV2-1/LCS2 & 1965 & 1965 & 740 & 473 & 33 & $\begin{array}{l}\text { accidental } \\
\text { explosion }\end{array}$ & 7 & 13 \\
\hline $\begin{array}{c}\text { RB } \\
\text { CBERS1/SACI }\end{array}$ & 1999 & 2000 & 740 & 431 & 210 & $\begin{array}{l}\text { accidental } \\
\text { explosion }\end{array}$ & 8 & 6 \\
\hline RB Nimbus 4 & 1970 & 1970 & 1075 & 376 & 235 & $\begin{array}{l}\text { accidental } \\
\text { explosion }\end{array}$ & 9 & 5 \\
\hline RB TES & 2001 & 2001 & 670 & 372 & 80 & $\begin{array}{l}\text { accidental } \\
\text { explosion }\end{array}$ & 10 & 12 \\
\hline USA-193 & 2006 & 2008 & 250 & 360 & 0 & $\begin{array}{c}\text { intentional } \\
\text { collision }\end{array}$ & 11 & 17 \\
\hline Cosmos 1275 & 1981 & 1981 & 980 & 346 & 289 & $\begin{array}{c}\text { explosion of } \\
\text { batteries }\end{array}$ & 12 & 4 \\
\hline Solwind(P78-1) & 1979 & 1985 & 530 & 285 & 0 & $\begin{array}{c}\text { intentional } \\
\text { collision }\end{array}$ & 13 & 15 \\
\hline RB Cosmos 2227 & 1992 & 1992 & 830 & 279 & 199 & $\begin{array}{l}\text { accidental } \\
\text { explosion }\end{array}$ & 14 & 8 \\
\hline RB Nimbus 6 & 1975 & 1991 & 1090 & 274 & 199 & $\begin{array}{l}\text { accidental } \\
\text { explosion }\end{array}$ & 15 & 7 \\
\hline RB NOAA 3 & 1973 & 1973 & 1515 & 201 & 179 & $\begin{array}{l}\text { accidental } \\
\text { explosion }\end{array}$ & 16 & 9 \\
\hline RB NOAA 5 & 1976 & 1977 & 1510 & 184 & 174 & $\begin{array}{l}\text { accidental } \\
\text { explosion }\end{array}$ & 17 & 10 \\
\hline
\end{tabular}

Table 3 compiled by the data from the US SSN SO catalog contains 17 breakups produced the most amount of fragments $[5,6,7]$. First, about some simple criteria of the danger of breakup of the $i$-th SO. Here $R_{1}\left(N_{1}^{i}\right)$ means the rank of danger of breakup defined as the position in the list of the SOs depending on the number of fragments $N_{1}^{i}$ produced just at the time of breakup (posted in descending order of $N_{1}^{i}$ ). Then $R_{t}\left(N_{t}^{i}\right)$ is the rank of danger of breakup defined as the position in the list of the SOs depending on the number of fragments $N_{t}^{i}$ remained in orbit up to the current time $t$ (in this case at January 2016), also posted in descending order of $N_{t}^{i}$. 
The values of $R_{1}$ (not only in this table, but with respect to the entire directory of SOs breakups as well) remain practically constant and can change only with the appearance of a particularly powerful destruction with the formation of a very large number of fragments. If so, such a breakup displaces the last one in the list. In contrast, the rank of danger of breakup $R_{t}$ (defined more objectively than $R_{1}$ ) may vary quickly and considerably over time and not only with the appearance of powerful destructions but also due to the different rates of reentry of fragments into the dense atmosphere. In this respect, particularly illustrative is the example of Cosmos 2421 (see Table 3, RB means rocket body).

However, one can observe the existence of breakups with the very time-resistant ranks. As one can see from Table 3, despite the significant change of the order of most SOs in ranging the danger of their breakups in time, the famous Fengyun-1C, Cosmos 2251, and Iridium 33 retain their primacy as to both criteria $\left(R_{1}\left(N_{1}^{i}\right)\right.$ and $\left.R_{t}\left(N_{t}^{i}\right)\right)$. That means that the power of their breakups overcomes the influence of time and the heights of orbits.

Table 3 and the ranks of danger of breakups $R_{1}$ and $R_{t}$ are based only on the facts of their detection and tracking their consequences by the data of the Space surveillance systems. So, these indexes and their dynamics are much more objective and informative than just speculative analysis.

The analysis of Table 3 allows drawing a number of interesting and practically useful conclusions. For example, comparing the breakups of Fengyun-1C and RB SPOT-1, one would think that the danger of this specific fact of breakup is determined primarily by the height of breakup which heavily impacts the rate of the fragments reentry and their decay. Nevertheless, both breakups happened in the same orbital range, though the rate of change of their danger $R_{2}$ strongly differs. The danger of the former remains stable $\left(R_{1}=R_{2}\right)$ but that of the latter sharply decreases - from rank 6 to rank 14. This could be the consequence of the significant impact of the character of breakup (the fragments sizes and the vectors of spray of fragments).

Table 3 also shows whether well or not the orbital range for testing kinetic weapon was chosen (see the ranks of Fengyun-1 C, USA-193 and Solwind (P78-1)) from the standpoint of space contamination.

In order to further refine the assessment of danger of breakup of the $i$-th $\mathrm{SO}$, it is important to consider the density $d_{i}$ of SOs distribution in the orbital region of the $i$-th SO motion and the average relative velocity $v_{i \text { avr }}$ of SOs approach namely in this orbital region (that is to replace $N_{1}\left(t_{t}\right)^{i}$ by $N_{1}\left(t_{t}\right)^{i} d_{i} v_{i}^{2}$ avr).

To assess the danger of breakups it is essential also to consider the degree, nature and character of fragmentation of SOs: the smaller the resulting fragments, the less dangerous for the functional spacecraft are the collision with them and the faster they will reenter the dense layers of the atmosphere.

It is useful to remind that when SOs collide, relatively more small OD is formed (as well, incidentally, of a large mass - of more than $50 \mathrm{~kg}[1,10]$ ) than in the explosion (see Fig. 3), which can be taken into account by the appropriate correcting (norming) coefficient.

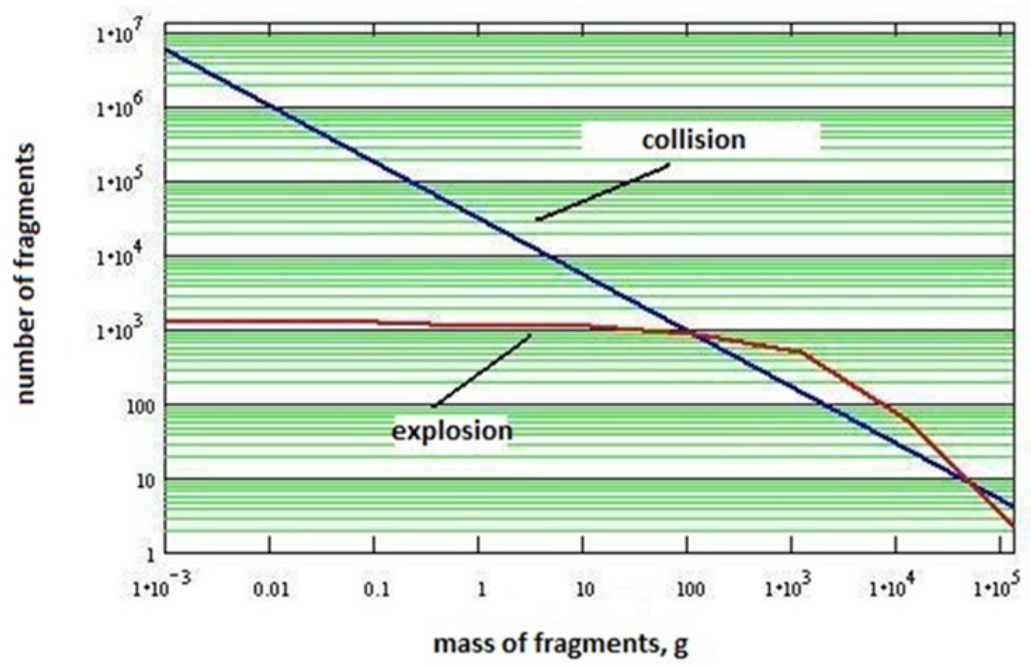

Figure 3. Comparison of the yield of fragments of various sizes as a result of explosion and supersonic collision [10]. 
When investigating the collision of a spacecraft with OD, in addition to the mass and relative velocity of the attacking particle, it is important to take into account in what place of the spacecraft and at what angle to its surface the collision happens as well as the density, frailness and melting point of the particle material.

In conclusion, the danger of consequences of collision of an active spacecraft with other SOs depends on many factors, some of them being very complicated to be taken into account.

\section{On Some Possible Constructions for Criteria of the Danger of SOs Collisions}

The next criterion can be suggested for assessing the danger of collision of an operational spacecraft with OD having the mass $m$ and the relative approaching velocity $v_{\text {rel }}$ hitting the spacecraft at the point having the susceptibility to impacts $k_{s}$ at the angle $\varphi$ to the surface of the spacecraft:

$$
W_{0}=k_{\text {norm }} k_{s} k_{a d} \sin \varphi m v_{r e l}^{2}
$$

where $k_{\text {norm }}$ is the norming coefficient, $k_{a d}$ - the coefficient taking account of any additional factors (for example, density, fragility, melting-point of the attacking OD, etc.).

On the base of this criterion it is possible to construct the criterion $W_{S}$ of the danger of collision of a given spacecraft with the tracked (cataloged) SOs in a given orbital region $S$. It is also possible to construct the criterion $W_{S}^{\text {avr }}$ of the danger of collision of a given spacecraft with small OD (or their flux) averaged for a given orbital region $S$ :

$$
W_{S}=k_{\text {norm }} \sum_{n=1}^{N} W_{0 n} p_{n}
$$

where $n$ is the SO's index, $p_{n}$ - the probability of collision of the spacecraft with the $n$-th SO, the summation being fulfilled over all cataloged SOs moving in this orbital region. It must be admitted that the calculation of some criterion's components (for example, coefficients $k_{s}, k_{a d}$ ) is problematic. Though it would be possible with the help of the appropriate engineering OD models and some other sources of information.

We underline that the accuracy of calculation of the probability of collisions depends on the precision of determination of the orbits, which in turn depends on the accuracy and frequency of obtaining the measurements of position and velocity of SOs. And one cannot count on a significant improvement of the latter in the near future because of a certain "staffing saturation" of both space surveillance systems (Russian and American) by the sensors and their service staff.

For heavily contaminated with non-catalogued small OD orbital regions, one can use the following more simple statistically locally averaged criterion:

$$
W_{S}^{\text {avr }}=k_{\text {norm }} k_{s}{ }^{\text {avr }} k_{\text {ad }}{ }^{\text {avr }} q \sin \varphi_{\text {avr }} m_{\text {avr }} v_{\text {avr }}^{2}
$$

where $v_{a v r}$ is the average relative approach velocity of SOs (or their fluxes) potentially colliding with a given spacecraft in a given orbital region $S, m_{\text {avr }}$ - the average mass of a debris particle in the flux, $q-$ the density of the incoming OD flux.

In the calculation of the averaged parameters $k_{s}^{a v r}, k_{a d}^{a v r}, \phi_{a v r}$, one can use the average characteristics of the incoming OD flows. And the narrower the orbital debris and shorter the time interval, the more accurate and definite the calculation of these characteristics. For this it is necessary an appropriate dynamic model of technogenic contamination of this orbital region $S$ with the necessary statistical characteristics (for example, $[12,13,14]$ ).

Since in most of orbital areas there are both individually controlled SOs and clusters of medium-sized and small debris described only statistically, it is natural to construct a differentiated estimate of the potential danger of collisions of a given spacecraft with OD (and with SOs in general) in a given orbital region $S$ :

$$
W_{\Sigma}=W_{S}+W_{S}^{a v r}=k_{\text {norm }}\left(\sum_{n=1}^{N} W_{0 n} p_{n}+k_{v}^{a v r} k_{a d}{ }^{a v r} q \sin \varphi_{\text {avr }} m_{\text {avr }} v_{\text {avr }}^{2}\right)
$$


Here, the first term in the right part of the equality is responsible for individually monitored (usually cataloged) SOs, and the second one - for statistically recorded fluxes of small OD in a given orbital region.

Perhaps to attain a more subtle structure of the estimate and the necessary compliance of the two components because of significant difference in peculiarities of large and small debris we will have to introduce the special norming coefficients for each of them $k_{\text {norm }}^{i}, i=1,2$.

Depending on the height of the examined orbital region, the values of these criteria (as well as the danger of collision itself) can vary widely versus both different densities of distribution of SOs in different orbital regions and altitude regimes of NES.

Moreover, both parameters themselves are able to significantly vary [1, 8]. So, in the low Earth orbital (LEO) region the average relative conjunction velocity of SOs $v_{a v r}$ equals approximately $10 \mathrm{~km}$ per second (the maximum one is $17 \mathrm{~km} / \mathrm{s}$ ), in the vicinity of semi-synchronous circular orbits it is about 4 $\mathrm{km}$ per second (the maximum one is $7.8 \mathrm{~km} / \mathrm{s}$ ). And in the geostationary belt $v_{\text {avr }} \approx 0.5 \mathrm{~km} / \mathrm{s}$, the maximum relative conjunction velocity theoretically is equal to $6 \mathrm{~km} / \mathrm{s}$. Although the latter is practically an unlikely case in view of the fact that in GEO (in contrast to LEO) all SOs are moving on the whole in the same direction $[1,8]$.

Using the suggested approach to evaluation of the potential danger of SOs breakups, it is possible to make a map of danger of collisions for different classes of SOs and different orbital regions in NES.

The greatest probability of collision of SOs is typical of LEO, especially in the height ranges from 700 $\mathrm{km}$ through $1000 \mathrm{~km}$ and from $1400 \mathrm{~km}$ through $1500 \mathrm{~km}$. The danger and probability of collisions, of course, are correlated with such a characteristic as the density of SOs in a given orbital region. However, some ones of the latter introduce significant corrections to this correlation. For instance, in the GEO belt where the density of SOs is rather high the probability of collisions and especially their danger are somewhat insignificant. This fact is accounted by the common motion of SOs in this region predominantly in one direction and also by low relative velocities of their conjunctions.

For determining the danger of collisions of a given spacecraft with OD or other active or passive satellites it is possible to confine oneself to a rather narrow orbital region and taking into account not only the orbit height but also other parameters - inclination, eccentricity, etc. This problem is inevitable, for example, when a designer should choose an appropriate orbit for the worked out spacecraft in a specific design as well as when deciding on and calculating an avoidance maneuver for some functional spacecraft. In this case the initial data on the contamination of the orbital region would be more definite and the results of calculation of the collision danger more accurate.

\section{Conclusions}

Since the assessments of hazard of the consequences of breakups of space objects and of their collisions are used both in the solution of problems of safety of space flights (in particular, when calculating the evasive maneuvers of the spacecraft from collision with debris) and space activities in general and in the development of new space projects and the construction of spacecraft, one should treat with caution the simplified approaches to the construction of such assessments and, if possible, to get rid of them. It should be taken into account as many as possible factors affecting the risks of the events (not only the orbital debris sizes).

The analysis of the danger ranks dynamics for space objects breakups in the past allows getting estimates of whether successfully or not the orbital regions for some space experiments were chosen.

The procedure of taking decision on the avoidance maneuver for an active spacecraft should include the weighed comparison of a deterministic constituent of the estimate of danger (corresponding to a possible collision with a particular cataloged space objects) and a statistical one (accounting noncataloged populations of small orbital debris). The proposed here estimates of collision danger take into account a wide variety of factors associated with the process being analyzed.

In constructing more accurate estimates, the bottleneck is, first of all, insufficient information on the density and dynamics of the motion of small orbital debris fractions. This requires improving the ways and means to observe them, and, accordingly, the flow models of small debris populations.

In view of the large shortage of small orbital debris measurements (due to the lack of sensors with appropriate capabilities) and taking into account significant danger of small orbital debris to space 
activities, it is extremely important to cooperate with the owners of all sources of such measurements available in the world. In particular, it would be very useful to establish a regular exchange of space objects catalogs, first of all, between the US and Russia's Space Surveillance Systems.

\section{References}

1. S Veniaminov, Space debris - a hazard to Mankind. 2-nd edition. RAS publ. Moscow, Ser. "Mechanics, guidance, informatics", 2013, 207 р. (Вениаминов С.С., Космический мусор - угроза человечеству. Изд. 2-е исправл. и дополн. Изд. ИКИ РАН, сер. механика, управление, информатика. 207 с., М., 2013 г., ISSN 2075-6836)

2. V.Adushkin, S. Veniaminov, S.Kozlov, M. Silnikov, Orbital missions safety - A survey of kinetic hazards // Acta astronautica, v. 126, pp.510-516, 2016;

3. S. Veniaminov, I. Oleynikov, E. Melnikov, Indices of growth of danger for space activities from orbital debris and the related mitigation measures // "Kinematics and Physics of Celestial Bodies", Allerton Press, Springer Link, v.32, №5, pp.227-232, 2016, ISSN0884-5913, doi:10.3103/S088459131605010X

4. The effect of rocket techniques on the environment, Moscow, Geos Publ. 2016, 795 р. (Воздействие ракетнокосмической техники на окружающую среду. Изд. «ГЕОС», М., 2016 г.)

5. P. Anz-Meador, Top Ten Satellite Breakups Reevaluated // Orbital Debris Quarterly News, v. 20, i. 1\&2, pp. April 2016.

6. Grego, Laura (2006), A Hystory of Anti-Satellite Weapons Programs, 2006; online: Union of Concerned Scientists, http://www.ucsusa.org/global_security/space_weapons/a-hystory-of-asat-programs.html

7. Kaufman, M., and White, J. (2008), Navy missile hits dying spy satellite, says Pentagon // Washington Post, 21 February 2008

8. V. Adushkin, S. Veniaminov, S. Kozlov, et al. Natural and technogeneous contamination of near-Earth space // Acta Astronautica, http://dx.doi.org/10.1016/j.actaastro.2016.12.038

9. A.Nazarenko, Space debris modeling, RAS publ. Moscow, Ser. "Mechanics, guidance, informatics", 2013,215 p.

(А. И. Назаренко, Моделирование космического мусора, ИКИ РАН, Москва, 2013 г.)

10. Potter, A. (1993), Early detection of Collisional cascading // Proceedings of the 1st European Conference on Space Debris, ESA/ESOC, Darmstadt, Germany, 1993

11. D. McKnight, The Need For Wake Debris Modeling // Orbital Debris Quarterly News, v. 2, i. 1, pp. 4-5, 1997

12. J. Opiela and A. Vavrin, New Version of DAS Now Available // Orbital Debris Quarterly News, v. 21, i. 1, pp. 4-7, 2017

13. M. Matney, P. Krisko, et al., ORDEM 3.0 Verification and Validation Findings // Orbital Debris Quarterly News, v. 20, i. $1 \& 2$, pp. 5, 7-10, 2016

14. P. Krisko, S. Flegel, et al., ORDEM 3.0 and MASTER-2009 Modeled Small Debris Population Comparison // Orbital Debris Quarterly News, v. 19, i. 2, pp. 4-6, 2015. 